\title{
Organic Crop Management Enhances Chicoric Acid Content in Lettuce
}

\author{
Channa B. Rajashekar ${ }^{1 *}$, Myung-Min Oh$^{2}$, Edward E. Carey ${ }^{3}$ \\ ${ }^{1}$ Department of Horticulture, Forestry and Recreation Resources, Kansas State University, Manhattan, USA; ${ }^{2}$ Department of Horti- \\ cultural Science, Chungbuk National University, Cheongju, South Korea; ${ }^{3}$ International Potato Center, Kumasi, Ghana. \\ Email: *crajashe@ksu.edu
}

Received July 23 ${ }^{\text {rd }}, 2012$; revised August $23^{\text {rd }}, 2012$; accepted August $30^{\text {th }}, 2012$

\begin{abstract}
L-chicoric acid is a dominant phenolic compound in lettuce (Lactuca sativa L.) and has been shown to accumulate in response to many abiotic stresses and crop management practices. It is a potent inhibitor of human immunodeficiency virus (HIV-1) integrase needed for the replication of this virus and for the productive infection of the host cell. L-chicoric acid has been found to act synergistically in combination with anti-HIV drugs used for treating acquired immunodeficiency disorder (AIDS). We show in this study that organic management practices increase the chicoric acid content by nearly 2 -fold compared to conventional management practices while they did not have a significant effect on the overall accumulation of phenolic compounds and antioxidants. Similar increase was observed in quercetin-3-O-glucoside under organic management. In addition, pre-plant fertilization decreased the levels of many phenolic compounds including chicoric acid under organic management unlike under conventional management. However, organically managed crop without pre-plant fertilization had better growth and produced about 2.5 times higher yield and higher chicoric acid content than did the conventionally managed crop. Thus, the results show that long term organic crop management practices, but avoiding pre-plant fertilization, can significantly enhance the yield of antiretroviral agent chicoric acid in lettuce.
\end{abstract}

Keywords: AIDS; Antiretroviral; Crop Production Practices; HIV-1; Organic Fertilization; Phytochemical

\section{Introduction}

Currently drug therapies for treating human immunodefiency virus (HIV-1), the causative agent of acquired immune deficiency syndrome (AIDS), target multiple enzymes that can disrupt the viral lifecycle [1-3]. For productive infection, this retrovirus needs to incorporate its cDNA into the host genome with the help of the viral enzyme, integrase [4]. Integrase activity is essential for viral replication, a key step in the infection of the host cell, and is inhibited by L-chicoric acid (decaffeoyltartaric acid) which is naturally found in a number of plants species. Extensive studies have shown that both in vivo and vitro chicoric acid is a potent and selective inhibitor of this enzyme with favorable therapeutic indices $[5,6]$. In addition, numerous synthetic analogs of chicoric acid have been examined for its efficacy as an antiretroviral agent with favorable results [7-9]. L-chicoric acid has been found to act synergistically when used in combination with drugs containing reverse transcriptase inhibitors and protease inhibitor and has been found to be equally effective against

${ }^{*}$ Corresponding author. both wild and drug resistant mutants of HIV-1 [1]. The first drug using integrase inhibitor (Raltegravir) was approved by the US Food and Drug Administration (FDA) in 2007 while still others are being actively tested in clinical trials [10]. The focus on integrase inhibitors, especially L-chicoric acid for developing successful anti-HIV drug therapy, has been a promising area of study [3,10-12].

Although chicoric acid has been identified in multiple plant species including Echinacea [13], dandelion [14], basil [15], and others [16], lettuce is particularly an attractive source of this phenolic compound since it is a commonly consumed leafy vegetable in many regions of the world including the US. Chicoric acid is a major phenolic compound in lettuce $[17,18]$ and can accumulate in significant amounts in response to various abiotic stresses including, heat shock, chilling, mild water stress and high light $[18,19]$. In addition to abiotic factors, many biotic factors can also influence the accumulation of phytochemicals in plants [20]. Therefore, crop management practices and growing conditions are likely to play an important role in affecting the phytochemical content [21-25] and thereby, providing promising practical strategies to enhance this phytochemical content in lettuce. 
To keep pace with the rapidly growing demand for organic foods in the US, organic production has been steadily growing over the past two decades [26,27]. The increasing popularity of organic food is partly based on the overwhelming consumer perception that they are healthy and are rich in health-promoting nutrients and phytochemicals. Although many studies tend to support this view [21,25], a broader review of studies on various crops under varied field conditions suggests that the impact of organic practices on phytochemicals in crops is rather less than conclusive $[28,29]$. However, our previous studies have shown that several abiotic factors including growing conditions can lead to accumulation of a number of phenolic compounds in lettuce grown under greenhouse and field conditions $[18,24]$. Based on these findings, in this study we examine the effects organic management practices on many phenolic compounds including chicoric acid in lettuce.

\section{Materials and Methods}

\subsection{Experimental Conditions and Plant Material}

Seeds of a green leaf lettuce, "Baronet" were germinated in plastic pots, $8 \mathrm{~cm} \times 8 \mathrm{~cm} \times 7 \mathrm{~cm}(\mathrm{~L} \times \mathrm{W} \times \mathrm{H})$, with a growing medium (Metro-Mix 350, Sun Gro, Canada). Seedlings were grown in a greenhouse in Manhattan at Kansas State University for 3 weeks until they were transplanted to field plots and certified organic plots (each plot $9.8 \mathrm{~m} \times 6.1 \mathrm{~m} ; \mathrm{L} \times \mathrm{W})$ at K-State Horticulture Research and Extension Center, Olathe, KS. Organic plots were managed organically for the past 5 years in compliance with USDA National Organic Program standards. The field trial was laid out on a completely randomized block design (CRBD) with 3 replications. Based on the analyses of soil samples (Kennebec silt loam) from K-State Horticulture Research and Extension Center, the amount of both organic and conventional fertilizers to be applied was determined. As the organic source, Hu-More $1 \mathrm{~N}-0.4 \mathrm{P}-0.8 \mathrm{~K}$ (composted cattle manure and alfalfa hay; Humalfa, Inc., Shattuck, OK, USA) was applied to each plot at $224 \mathrm{~kg} \cdot \mathrm{ha}^{-1}$ N. Commercial synthetic fertilizer 13N-13P-13K (Greenskeeper Select Lawn and Garden Fertilizer, T and N, Inc., Foristell, MO, USA) was used for conventional cultivation at $112 \mathrm{~kg} \cdot \mathrm{ha}^{-1} \mathrm{~N}$. Fertilizers were incorporated into soil 1 week before transplanting the seedlings to the field plots. The plots were irrigated though the drip tape line. Both organic and conventional plots were divided into two groups; namely control (C) that did not receive any fertilizers and treated $(\mathrm{F})$ that received either organic or synthetic fertilizer. From our preliminary studies, high fertility had an adverse effect on the accumulation of phenolic compounds in lettuce and therefore, control plots were selected not to receive any fertilizer application.

\subsection{Total Phenolic Content}

For total phenolic content analysis, 3 leaf samples per treatment from 3 randomly selected plants were collected at the time of harvest. Samples were collected from fully expanded, just matured leaves and frozen immediately in liquid $\mathrm{N}_{2}$ before transferring them to the laboratory where they were stored at $-20^{\circ} \mathrm{C}$ until use. The total phenolic content of lettuce leaves was determined by a modified Folin-Ciocalteu reagent method [30]. About $1 \mathrm{~g}$ of fresh leaf tissue was macerated in liquid $\mathrm{N}_{2}$ with mortar and pestle and mixed with $3 \mathrm{~mL} 80 \%(\mathrm{v} / \mathrm{v})$ acetone. The sample was placed into a $1.5 \mathrm{~mL}$ tightly covered micro-tube and incubated in darkness at $4^{\circ} \mathrm{C}$ overnight. Subsequently, the sample was centrifuged at $1000 \mathrm{rpm}$ for $2 \mathrm{~min}$ and the supernatant was used as phenolic extract. A mixture of $135 \mu \mathrm{L}$ distilled water, $750 \mu \mathrm{L}$ 1/10 dilution FolinCiocalteu reagent (Sigma-Aldrich, St. Louis, MO, USA) and $600 \mu \mathrm{L} 7.5 \%(\mathrm{w} / \mathrm{v}) \mathrm{Na}_{2} \mathrm{CO}_{3}$ was added to $50 \mu \mathrm{L}$ of phenolic extract in a $1.5 \mathrm{~mL}$ micro-tube. After vortexing for $10 \mathrm{~s}$, the mixture was incubated at $45^{\circ} \mathrm{C}$ in a water bath for $15 \mathrm{~min}$. Samples were allowed to cool at room temperature before measuring the absorbance at $765 \mathrm{~nm}$ by a spectrophotometer (U-1100, Hitachi Ltd. Japan). A blank was prepared using $50 \mu \mathrm{L} 80 \%(\mathrm{v} / \mathrm{v})$ acetone. A gallic acid standard curve was prepared from a freshly made stock solution of $1 \mathrm{mg} \cdot \mathrm{mL}^{-1}$ gallic acid (Acros Organics, Belgium) in $80 \%(\mathrm{v} / \mathrm{v})$ acetone.

\subsection{Antioxidant Capacity}

The sample collection for the measurement of antioxidant capacity was the same as those for the analysis of total phenolic content. A modified ABTS (Aminobenzotriazole) method was used to analyze the antioxidant capacity of lettuce leaves [31]. Antioxidants were extracted by $5 \mathrm{~mL}$ extraction solution [acetone: water: acetic acid $=70: 29.5$ : 0.5 , (v:v:v)] from about $1 \mathrm{~g}$ of lettuce frozen in liquid $\mathrm{N}_{2}$. A $1 \mathrm{~mL}$ of the extract placed into a $1.5 \mathrm{~mL}$ tightly covered micro-tube was incubated in darkness at $-20^{\circ} \mathrm{C}$ overnight. Subsequently, the solution was centrifuged at 1000 rpm for 2 min. ABTS [(2.5 mM) (Roche Diagnostics, Indianapolis, IN, USA)] stock solution was prepared and $0.4 \mathrm{~g}$ of $\mathrm{MnO}_{2}$ (Acros Organics, Belgium) was added to $20 \mathrm{~mL}$ of stock solution to generate ABTS radical cations $\left(\right.$ ABTS $\left.^{*}\right)$, stirring the mixture occasionally for $30 \mathrm{~min}$ at room temperature. Excess $\mathrm{MnO}_{2}$ was removed by filtration first using a filter paper (No. 1, Whatman plc., UK) through a Buchner funnel, and then with a $0.2 \mu \mathrm{M}$ syringe-end filter (Millipore Corp., Bedford, MA, USA). The ABTS* solution was incubated at $30^{\circ} \mathrm{C}$ in a water bath during the analysis and was diluted to an absorbance $0.7( \pm 0.02)$ at $730 \mathrm{~nm}$ with $5 \mathrm{mM}$ PBS [phosphate buffer saline, $\mathrm{pH} 7.4$, ionic strength $(150 \mathrm{mM} \mathrm{NaCl})]$. A $100 \mu \mathrm{L}$ of the extract was add to $1 \mathrm{~mL}$ of ABTS $^{*}$ solution. The 
solution was vortexted for $10 \mathrm{~s}$ and its absorbance was recorded at $730 \mathrm{~nm}$ by a spectrophotometer (U-1100, Hitachi Ltd. Japan) at the end of 1 min reaction time. Trolox [(6-Hydroxy-2,5,7,8-tetramethylchroman-2-carboxylic acid) (Acros Organics, Belgium)] was used as a standard for quantification.

\subsection{High-Performance Liquid Chromatography (HPLC) Analyses}

The extraction of phenolic compounds from lettuce leaves was carried out as described by Nicolle, et al. [32] with minor modifications. Three leaves collected from separate plants at the time of harvest were used per treatment. Frozen leaf sample $(1 \mathrm{~g})$ macerated in a mortar with a pestle using liquid $\mathrm{N}_{2}$ was mixed with $50 \mathrm{~mL}$ of $70 \%$ methanol at $80^{\circ} \mathrm{C}$ for $1 \mathrm{~min}$. After stirring at room temperature for $1 \mathrm{~h}$, the mixture was filtered through a filter paper (No. 1, Whatman plc., UK). The extract $(25 \mathrm{~mL})$ was evaporated to dryness by a rotary evaporator (Rotavapor R110, Brinkmann Instruments, Inc., Westbury, NY, USA) under reduced pressure at $50^{\circ} \mathrm{C}$ and then resuspended in $5 \mathrm{~mL}$ of $70 \%$ methanol. The concentrated solution was filtered through a $0.45 \mu \mathrm{m}$ filter ascrodisc (Millex, Millipore Corp., Bedford, MA, USA) before HPLC analysis. A $5 \mu \mathrm{L}$ aliquot of the sample extract was injected into a HPLC system equipped with an autosampler (SpectraSYSTEM AS1000, Thermo Separation Products, San Jose, CA, USA), a pump (HP 1050, Hewlett Packard, Palo Alto, CA, USA), an integrator (HP 3396, Hewlett Packard, Palo Alto, CA, USA), and an UV/VIS detector (Acutect 500, Thermo Separation Products, San Jose, CA, USA). Phenolic compounds were separated from the extract using a column (Discovery BIO Wide Bore C-18, $15 \mathrm{~cm} \times 4.6 \mathrm{~mm}, 5 \mu \mathrm{m}$, Supelco, Inc., Bellefonte, PA, USA) coupled to a guard column (Discovery BIO Wide Bore C-18, $2 \mathrm{~cm} \times 4 \mathrm{~mm}, 5 \mu \mathrm{m}$, Supelco, Inc., Bellefonte, PA, USA) at $60^{\circ} \mathrm{C}$. The extracts were eluted with eluant $A$ $\left[\mathrm{H}_{2} \mathrm{O}: \mathrm{CH}_{3} \mathrm{COOH}=338: 1(\mathrm{v} / \mathrm{v})\right]$ and eluant $\mathrm{B}$

$\left[\mathrm{H}_{2} \mathrm{O}: \mathrm{C}_{4} \mathrm{H}_{10} \mathrm{O}: \mathrm{CH}_{3} \mathrm{COOH}=330: 8: 1(\mathrm{v} / \mathrm{v} / \mathrm{v})\right]$ at a flow of $1.8 \mathrm{~mL} \cdot \mathrm{min}^{-1}$. Peaks from the sample were identified and quantified at $330 \mathrm{~nm}$ by comparing with standard compounds which included chlorogenic acid (Sigma-Aldrich, St. Louis, MO, USA), caffeic acid (Sigma-Aldrich, St. Louis, MO, USA), quercetin-3-O-glucoside (Sigma-Aldrich, St. Louis, MO, USA), chicoric acid (Indofine Chemical Co., Inc., Hillsborough, NJ, USA), and luteolin-7-Oglucoside (Indofine Chemical Co., Inc., Hillsborough, NJ, USA).

\subsection{Plant Growth Characteristics}

Data on biomass accumulation in lettuce were collected at 5 and 7 weeks after germination. Fresh and dry weights of roots and shoots were determined using six lettuce plants per each treatment. Immediately after collecting samples, fresh weights of roots and shoots were measured in the field. The samples were dried at $70^{\circ} \mathrm{C}$ in an oven for $3 \mathrm{~d}$ for the determination of their dry weights.

\subsection{Statistical Analysis}

Analysis of variance (ANOVA) was performed by the statistical analysis system program (SAS Institute, Inc., Cary, NC, USA). Duncan's multiple range test was used to compare means.

\section{Results and Discussion}

There were no significant differences in the total phenolic content or antioxidant capacity between lettuce crops grown organically and conventionally with or without fertilization (Figure 1). However, organic management enhanced the accumulation of some key phenolic compounds in lettuce. Chicoric acid was the dominant phenolic compound in lettuce followed by chlorogenic acid. Organic management of the crop resulted in a significant increase in the levels of chicoroc acid and quercetin glycoside in lettuce over conventional management. The conspicuous increase was in the chicoric acid content which nearly doubled by organic management practices while no differences were observed in amount of other phenolic compounds including chlorogenic and caffeic acids and luteolin glycoside between organic and conventional management practices (Figure 2). Similar results have been observed in lettuce in response to a number of abiotic stresses in a growth chamber study [18]. In our previous study, levels of chicoric acid and other phenolic compounds increased significantly due to a brief exposure of lettuce plants to stress conditions including chilling, heat shock and high light $\left(800 \mu \mathrm{mol} / \mathrm{m}^{2} / \mathrm{s}\right)$ with high light producing the largest response of a four-fold increase over the control. This was confirmed in a recent field study with green and red leaf lettuce, where lettuce grown in open field with

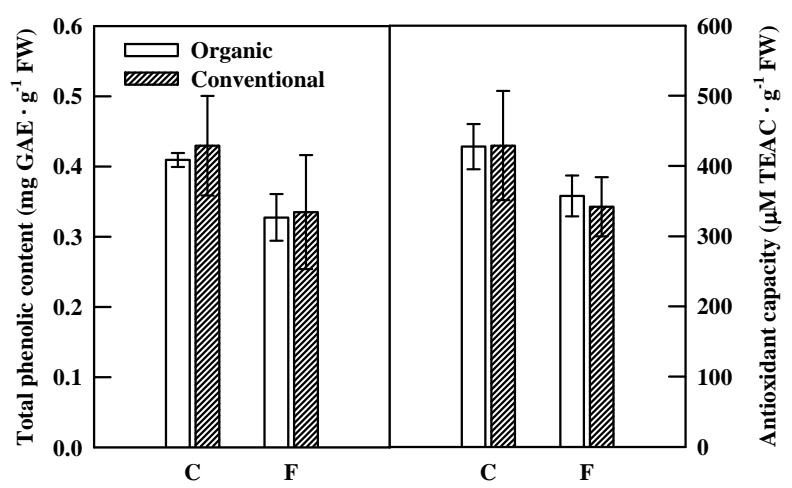

Figure 1. Total phenolic content and antioxidant capacity in organically (open bars) and conventionally (shaded bars) grown lettuce plants at the time of harvest. $C$ and $F$ indicate control group and fertilizer group, respectively. 


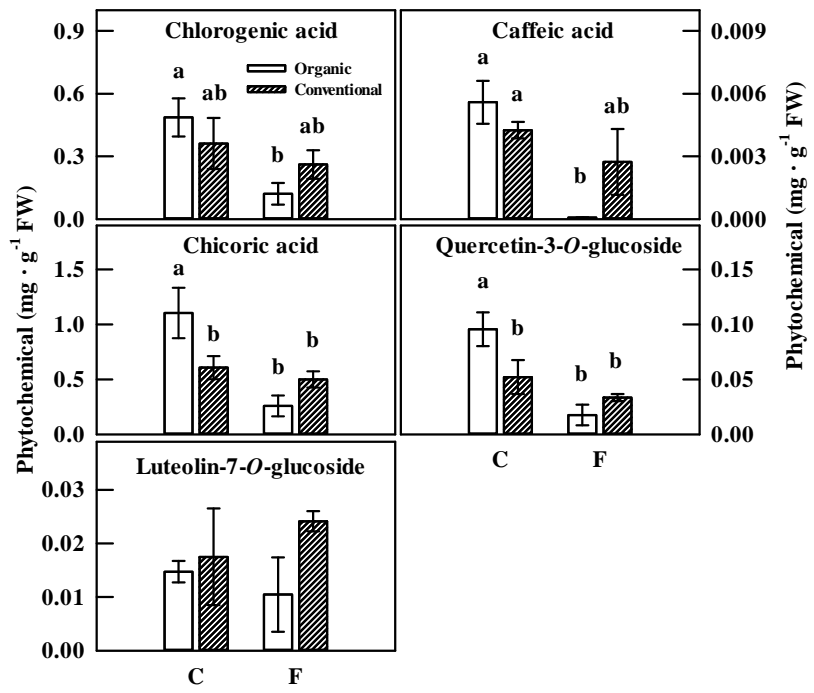

Figure 2. Phenolic compounds of organically (open bars) and conventionally (shaded bars) grown lettuce plants at the time of harvest. $\mathrm{C}$ and $\mathrm{F}$ indicate control group and fertilizer group, respectively. Differences within a phytochemical indicated by different letters are significant at $\mathbf{p}=0.05$.

exposure to direct solar radiation produced more chicoric acid than did the crop grown in high tunnels [24]. Similarly, higher chicoric acid was found to accumulate in young lettuce seedlings grown in open field than under greenhouse conditions [33]. In addition, recurring mild water stress in lettuce was also found to increase chicoric acid by 2 -fold and the expression of gene, phenylalanine ammonia-lyase (PAL), which encodes for the gateway enzyme in the phenylproponoid pathway responsible for the biosynthesis of a wide range of phenolic compounds [19].

The increase in the amount of chicoric acid in lettuce due to organic management was the largest (more than $0.8 \mathrm{mg} / \mathrm{g} \mathrm{FW}$ ). Chicoric acid has been extensively investigated as an effective inhibitor of HIV-1 integrase, an antiretroviral agent for developing effective therapies against AIDS. Chicoric acid was found to be a potent component in combination therapy and can act in a synergistic fashion with drugs that target other enzymes including Zidovudine, the first antiretroviral drug approved (nucleoside analog reverse transcriptase inhibitor) and a Nelfinavir (a protease inhibitor) [1]. Interestingly if chicoric acid was included in the drug regimen, the dose of these retroviral drugs could be reduced by more than $33 \%$ to obtain equivalent effect in controlling HIV-1 [34]. This may have the distinct advantage of reducing both the potential toxicity and the high cost associated with these drugs in treating AIDS.

However, it should be noted that although large increases in chicoric acid and quercetin glycoside were noted with organic management, this trend was neither reflected in the overall content of phenolic compounds nor in the total antioxidant activity. In a study comparing organic and con- ventional management practices in lettuce, Zhao, et al. [35] observed similar results where no significant differences in either total phenolic accumulation or in some individual phenolic compounds that did not include chicoric acid.

Fertilization generally reduced the overall phenolic content and antioxidant capacity in both organically and conventionally managed crops. It significantly reduced the accumulation of some key phenolic compounds including chicoric acid, chlorogenic acid, caffeic acid and quercetin glycoside only under organic management while it did not have any effect on the accumulation of these compounds under conventional management. In fact, caffeic acid accumulation was completely suppressed by organic fertilization in lettuce but not in conventionally managed crop. It is interesting that organically managed plants, not receiving any fertilizers, had 4 fold higher chicoric acid content than those receiving fertilization while there was no effect of fertilization in conventionally managed crop. Nitrogen over fertilization has been found to have a negative effect on crop quality by decreasing polyphenol content $[36,37]$. Conversely, nutrient deficiency, especially nitrogen has been found to induce phytochemicals such as ascorbic acid, flavanoids, and flavonols in Arabidopsis and tomato [38-41]. Similarly, the deficiency of other nutrients such as phosphorous, sulfur, and zinc also had an impact on the phytochemicals and related enzymes in several plant species $[39,40,42]$. Our results show that organically managed crops respond differently to fertilizations perhaps because they present unique set of conditions such as slow availability of soil nutrients and enhanced microbial activity $[43,44]$, particularly with regard to some specific microbial interactions with plant roots, which are known to induce the accumulation of secondary metabolites in plants $[45,46]$. The field plots used in our study have been managed organically for the last 5 years and thus, it is reasonable to expect the presence of a favorable root-microflora interaction which may promote phytochemical accumulation in lettuce crop.

With regard to the growth of lettuce plants, organically grown lettuce produced about 2.5 fold higher shoot biomass (fresh weight basis) at the time of harvest (7 week old) than its conventional counterpart with no fertilization (Table 1). Pre-plant application of organic fertilizers to the crop, although producing an unfavorable effect on the chicoric acid content, did not have any significant effect on fresh shoot weight at the time of harvest. The organic plots used here were managed organically for extended period of time and it is likely that they have built up a basal fertility level. Furthermore, addition of organic fertilization will make nutrients available at a slower rate which is likely to result in a rather steady and slower response in plant growth and biomass accumulations. However, in conventional plots, with fertilization, shoot biomass increased but was similar to that grown under organic conditions both at 5 and 7 week stages. Similar trend 
Table 1. Fresh and dry weights of organically and conventionally managed lettuce plants at 5 weeks and 7 weeks (at harvest). $\mathrm{C}$ and $\mathrm{F}$ indicate control group, without fertilizers, and fertilizer group, respectively. The values are the means $(n=6)$ with significance at $\mathbf{p}=0.05\left({ }^{*}\right), 0.01\left(^{* *}\right)$ or $0.001\left({ }^{* * *}\right)$.

\begin{tabular}{|c|c|c|c|c|c|c|c|c|c|}
\hline \multirow{3}{*}{ Soil management } & \multirow{3}{*}{ Fertilization } & \multicolumn{4}{|c|}{5 weeks } & \multicolumn{4}{|c|}{7 weeks } \\
\hline & & \multicolumn{2}{|c|}{ Fresh weight (g) } & \multicolumn{2}{|c|}{ Dry weight (g) } & \multicolumn{2}{|c|}{ Fresh weight (g) } & \multicolumn{2}{|c|}{ Dry weight (g) } \\
\hline & & Shoot & Root & Shoot & Root & Shoot & Root & Shoot & Root \\
\hline \multirow{2}{*}{ Organic } & $\mathrm{C}$ & $21.1 \mathrm{~b}$ & $2.3 \mathrm{a}$ & $1.7 \mathrm{ab}$ & $0.15 \mathrm{ab}$ & $250.5 \mathrm{a}$ & $9.1 \mathrm{~b}$ & $15.7 \mathrm{a}$ & $0.85 \mathrm{~b}$ \\
\hline & $\mathrm{F}$ & $30.7 \mathrm{a}$ & $3.1 \mathrm{a}$ & $2.4 \mathrm{a}$ & $0.19 \mathrm{a}$ & $313.2 \mathrm{a}$ & $13.1 \mathrm{a}$ & $18.6 \mathrm{a}$ & $1.19 \mathrm{a}$ \\
\hline \multirow{2}{*}{ Conventional } & $\mathrm{C}$ & $12.1 \mathrm{c}$ & $1.7 \mathrm{~b}$ & $1.1 \mathrm{~b}$ & $0.12 \mathrm{~b}$ & $97.0 \mathrm{~b}$ & $4.9 \mathrm{c}$ & $6.8 \mathrm{~b}$ & $0.42 \mathrm{c}$ \\
\hline & $\mathrm{F}$ & $28.8 \mathrm{ab}$ & $3.2 \mathrm{a}$ & $2.3 \mathrm{a}$ & $0.19 \mathrm{a}$ & $230.2 \mathrm{a}$ & $10.5 \mathrm{ab}$ & $14.5 \mathrm{a}$ & $0.8 \mathrm{~b}$ \\
\hline \multicolumn{2}{|c|}{ Significance } & $* *$ & $* *$ & $* *$ & * & $* * *$ & ** & $* * *$ & $* * *$ \\
\hline
\end{tabular}

was also observed in the accumulation of biomass in the roots. The results show that in organically managed lettuce, there was no difference in the crop yields between pre-plant fertilization and no fertilization. However, avoiding pre-plant fertilization did have the additional benefit of increased chicoric acid content in the leaves. Thus, the results show that adoption of long term organic production practices but avoiding pre-plant fertilization is beneficial in enhancing the antiretroviral agent chicoric acid in lettuce by increasing both its content and the crop yield relative the conventionally managed crop.

\section{Conclusion}

L-chicoric acid, an antiretroviral agent, is a dominant phenolic compound in lettuce and its accumulation is affected by a number of extrinsic factors including crop production and management practices. The results from this study indicate that organic management practices of lettuce can increase the L-chiocric acid content of leaves nearly 2-fold along with quercetin glycoside content compared to the conventional management practices. However, pre-plant application of fertilizers in organically managed crop resulted in reduced accumulation of many phytochemiclas including L-chicoric, chlorogenic and caffeic acids but did not have any significant effect on the crop yield. Therefore, adopting a long term organic production practices without the pre-plant fertilization is a successful practical strategy to significantly enhance the levels of L-chicoric acid in lettuce crop.

\section{REFERENCES}

[1] K. K. Beale and W. E. Robinson Jr., "Combination of Reverse Transcriptase, Protease, and Integrase Inhibitors can be Synergistic in Vitro against Drug-Sensitive and RT Inhibitor-Resistant Molecular Clones of HIV-1," Antivi- ral Research, Vol. 46, No. 3, 2000, pp. 223-232. doi:10.1016/S0166-3542(00)00083-8

[2] P. Cos, M. Maes, D. V. Berghe, N. Hermans, L. Pieters and A. Vlietinck, "Plant Substances as Anti-HIV Agents Selected according to Their Putative Mechanism of Action," Journal of Natural Products, Vol. 67, No. 2, 2004, pp. 284-293. doi:10.1021/np034016p

[3] D. J. McColl and X. Chen, "Strand Transfer Inhibitors of HIV-1 Integrase: Bringing in a New Era of Antiretroviral Therapy," Antiviral Research, Vol. 85, No. 1, 2010, pp. 101-118. doi:10.1016/j.antiviral.2009.11.004

[4] R. L. LaFemina, C. L. Schneider, H. L. Robbins, P. L. Callahan, K. LeGrow, E. Roth, W. A. Schleif and E. A. Emini, "Requirement of Active Human Immunodeficiency Virus Type 1 Integrase Enzyme for Productive Infection of Human T-Lymphoid Cells," Journal of Virology, Vol. 66, 1991, pp. 7414-7419.

[5] W. E. Robinson Jr., M. O. Reinecke, S. Abdel-Malek, Q. Jia and S. A. Chow, "Inhibitors of HIV-1 Replication that Inhibit HIV Integrase," Proceedings of National Academy of Sciences, Vol. 93, No. 13, 1996, pp. 6326-6331. doi:10.1073/pnas.93.13.6326

[6] R. A. Reinke, D. J. Lee, B. R. McDougall, P. J. King, J. Victoria, Y. Mao, X. Lei, M. G. Reinecke and W. E. Robinson Jr., "L-Chicoric Acid Inhibits Human Immunodeficiency Virus Type 1 Integration in Vivo and Is a Noncompetitive Reversible Inhibitor of HIV-1 Integrase in Vitro," Virology, Vol. 326, No. 2, 2004, pp. 203-219. doi:10.1016/j.virol.2004.06.005

[7] Z. Lin, N. Neamati, H. Zhao, Y. Kiryu, J. A. Turpin, C. Aberham, K. Strebel, K. Kohn, M. Witvrouw, C. Pannecouque, Z. Debyser, E. D. Clercq, W. G. Rice, Y. Pommier and T. R. Burke Jr., "Chicoric Acid Analogues as HIV-1 Integrase Inhibitors," Journal of Medicinal Chemistry, Vol. 42, No. 8, 1999, pp. 1401-1414. doi: $10.1021 / \mathrm{jm} 980531 \mathrm{~m}$

[8] D. C. Meadows, T. B. Mathews, T. W. North, M. J. Hadd, C. L. Kuo, N. Neamati and J. Gervay-Hague, "Synthesis and Biological Evaluation of Germinal Disulfones as 
HIV-1 Integrase Inhibitors," Journal Medicinal Chemistry, Vol. 48, No. 14, 2005, pp. 4526-4534.

doi:10.1021/jm049171v

[9] T. T. Charvat, D. J. Lee, W. E. Robinson and A. R. Chamberlin, "Design, Synthesis, and Biological Evaluation of Chicoric Acid Analogs as Inhibitors of HIV-1 Integrase," Bioorganic Medicinal Chemistry, Vol. 14, No. 13, 2006, pp. 4552-4567. doi:10.1016/j.bmc.2006.02.030

[10] J. Blanco, V. Varghese, S. Rhee, J. M. Gatell and R. W. Shafer, "HIV-1 Integrase Inhibitor Resistance and Its Clinical Implications," Journal of Infectious Diseases, Vol. 203, No. 9, 2011, pp. 1204-1214. doi:10.1093/infdis/jir025

[11] D. C. Crosby, X. Lei, C. G. Gibbs, B. R. McDougall, W. E. Robinson Jr. and M. G. Reinecke, "Design, Synthesis, and Biological Evaluation of Novel Hybrid Dicaffeoyltartaric/Diketo Acid and Tatrazole-Substituted L-chicoric Acid Analogue Inhibitors of Human Immunodeficiency Virus Type 1 Integrase," Journal of Medicinal Chemistry, Vol. 53, No. 22, 2010, pp. 8161-8175. doi:10.1021/jm1010594

[12] D. C. Crosby and W. E. Robinson Jr., "Dicaffeoyltartaric Acid and Dicaffeoylquinic Acid HIV Integrase Inhibitors, in HIV-1 Integrase: Mechanism and Inhibitor Design (Ed. N. Neamati)," John Wiley and Sons, Hoboken, 2011, pp. 341-362. doi:10.1002/9781118015377.ch23

[13] R. B. Wills and D. L. Stuart, "Alkylamaide and Chicoric Acid Levels in Echinacea purpurea Grown in Australia," Food Chemistry, Vol. 67, No. 4, pp. 385-388. doi:10.1016/S0308-8146(99)00129-6

[14] K. Schutz, D. R. Kammerer, R. Carle and A. Schieber, "Characterization of Phenolic Acids and Flavonoids in Dandelion (Taraxacum officinale WEB. ex WIGG) Root and Herb by High-performance Liquid Chromatography/Electrospray Ionization Mass Spectrometry, Rapid Communication in Mass Spectrometry, Vol. 19, No. 2, 2005, pp. 179-186. doi:10.1002/rcm.1767

[15] J. Lee and C. F. Scagel, "Chicoric Acid found in Basil (Ocimum basilicum L.) Leaves," Food Chemistry, Vol. 115, No. 2, 2009, pp. 650-656. doi:10.1016/j.foodchem.2008.12.075

[16] I. D. Chkhikvishvili and G. I. Kahrebava, "Chicoric and Chlorogenic Acids in Plant Species from Georgia," Applied Biochemistry and Microbiology, Vol. 37, No. 2, 2001, pp. 188-191. doi:10.1023/A:1002888016985

[17] K. Amimoto and H. Fukui, "Quantitative Differences in Biologically Active Components among Hydroponically Cultured Lettuce and Endive Cultivars," Acta Horticulturae, Vol. 440, 1996, pp. 338-343.

[18] M. M. Oh, E. E. Carey and C. B. Rajashekar, "Environmental Stresses Induce Health-Promoting Phytochemicals in Lettuce," Plant Physiology and Biochemistry, Vol. 47, No. 7, 2009, pp. 578-583. doi:10.1016/j.plaphy.2009.02.008

[19] M. M. Oh, E. E. Carey and C. B. Rajashekar, "Regulated Water Deficits Improve Phytochemical Concentration in Lettuce," Journal of American Society for Horticultural Science, Vol. 135, 2010, pp. 223-229.

[20] R. A. Dixon and N. L. Paiva, "Stress-Induced Phenyl- propanoid Metabolism," Plant Cell, Vol. 7, No. 7, 1995, pp. 1085-1097. doi:10.1105/tpc.7.7.1085

[21] A. E. Mitchell, Y. Hong, E. Koh, D. M. Barrett, D. E. Bryant, R. F. Denison and S. Kaffka, "Ten-Year Comparison of the Influence of Organic and Conventional Crop Management Practices on the Content of Flavonoids in Tomatoes," Journal of Agricultural and Food Chemistry, Vol. 55, No. 15, 2007, pp. 6154-6159. doi:10.1021/jf070344+

[22] D. Treutter, "Managing Phenol Content in Crop Plants by Phytochemical Farming and Breeding-Visions and Constraints," International Journal of Molecular Sciences, Vol. 11, No. 3, 2010, pp. 807-857. doi:10.3390/ijms11030807

[23] C. B. Rajashekar, E. E. Carey, X. Zhao and M. M. Oh, "Health-Promoting Phytochemicals in Fruits and Vegetables: Impact of Abiotic Stresses and Crop Production Practices," Functional Plant Science and Biotechnology, Vol. 1, 2009, pp. 30-38.

[24] M. M. Oh, E. E. Carey and C. B. Rajashekar, "Antioxidant Phytochemicals in Lettuce in High Tunnels and Open Field," Horticulture, Environment and Biotechnology, Vol. 52, No. 2, 2011, pp. 133-139. doi:10.1007/s13580-011-0200-y

[25] X. Zhao, T. Iwamoto and E. E. Carey, "Antioxidant Capacity of Leafy Vegetables as Affected by High Tunnel Environment, Fertilisation and Growth Stage," Journal of the Science of Food and Agriculture, Vol. 87, No. 14, 2007, pp. 2692-2699. doi:10.1002/jsfa.3032

[26] L. Oberholtz, C. Dimitri and C. Greene, "Price Premiums Hold on as US Organic Produce Market Expands," Outlook Report VGS30801, USDA Economic Research Service, Washington DC, 2005.

[27] OTA (Organic Trade Association), “Organic Sales Reach \$31 billion," 2012.

http://www. naturalproductsinsider.com/

[28] D. Bourn and J. A. Prescott, "A Comparison of the Nutritional Value, Sensory Qualities, and Food Safety of Organically and Conventionally Produced Foods," Critical Reviews in Food Science and Nutrition, Vol. 42, No. 1, 2002, pp. 1-34. doi:10.1080/10408690290825439

[29] J. E. Young, X. Zhao, E. E. Carey, R. Welti, S. Yang and W. Wang, "Phytochemical Phenolics in Organically Grown Vegetables," Molecular Nutrition and Food Research, Vol. 49, No. 12, 2005, pp. 1136-1142. doi: $10.1002 / \mathrm{mnfr} .200500080$

[30] J. C. Pennycooke, S. Cox and C. Stushnoff, "Relationship of Cold Acclimation, Total Phenolic Content and Antioxidant Capacity with Chilling Tolerance in Petunia (Petunia $\times$ hybrida)," Environmental Experimental Botany, Vol. 53, No. 2, 2005, pp. 225-232. doi:10.1016/j.envexpbot.2004.04.002

[31] J. M. Awika, L. W. Rooney, X. Wu, R. L. Prior and L. Cisneros-Zevallos, "Screening Methods to Measure Antioxidant Activity of Sorghum (Sorghum bicolor) and Sorghum Products," Journal of Agricultural Food Chemistry, Vol. 51, No. 23, 2003, pp. 6657-6662. doi:10.1021/jf034790i

[32] C. Nicolle, A. Carnat, D. Fraisse , J. Lamaison, E. Rock, 
H. Michel, P. Amouroux and C. Remesy, "Characterisation and Variation of Antioxidant Micronutrients in Lettuce (Lactuca sativa folium)," Journal of the Science of Food and Agriculture, Vol. 84, No. 15, 2004, pp. 20612069. doi:10.1002/jsfa.1916

[33] A. Romani, P. Pimnelli, C. Galardi, G. Sani, A. Cimato and D. Heimler, "Polyphenols in Greenhouse and OpenAir-Grown Lettuce," Food Chemistry, Vol. 79, No. 3, 2002, pp. 337-342. doi:10.1016/S0308-8146(02)00170-X

[34] W. E. Robinson Jr., "L-Chicoric Acid, an Inhibitor of Human Immunodeficiency Virus Type 1 (HIV-1) Integrase, Improves on the in Vitro Anti-HIV-1 Effect of Zidovudine Plus a Protease Inhibitor (AG1350)," Antiviral Research, Vol. 39, No. 2, 1998, pp. 101-111. doi:10.1016/S0166-3542(98)00037-0

[35] X. Zhao, E. E. Carey, J. E. Young, W. Wang and T. Iwamoto, "Influences of Organic Fertilization, High Tunnel Environment, and Postharvest Storage on Phenolic Compounds in Lettuce," HortScience, Vol. 42, 2007, pp. 71-76.

[36] R. Fernández-Escobar, G. Beltrán, M. A. Sánchez-Zamora, J. García-Novelo, M. P. Aquilera and M. Uceda, "Olive Oil Quality Decreases with Nitrogen Over-Fertilization," HortScience, Vol. 41, 2006, pp. 215-219.

[37] C. Leser and D. Treutter, "Effects of Nitrogen Supply on Growth, Contents of Phenolic Compounds and Pathogen (scab) Resistance of Apple Trees," Physiologia Plantarum, Vol. 123, No. 1, 2005, pp. 49-56. doi:10.1111/j.1399-3054.2004.00427.x

[38] M. Bongue-Bartelsman and D. A. Philips, "Nitrogen Stress Regulates Gene Expression of Enzymes in the Flavonoid Biosynthetic Pathway of Tomato," Plant Physiology and Biochemistry, Vol. 33, 1995, pp. 539-546.

[39] A. Kandlbinder, I. Finkemeier, D. Wormuth, M. Hanitzsch and K. Dietz, "The Antioxidant Status of Photosynthesizing Leaves under Nutrient Deficiency: Redox Regulation, Gene Expression and Antioxidant Activity in Arabidopsis thaliana," Physiologia Plantarum, Vol. 120,
No. 1, 2004, pp. 63-73 doi:10.1111/j.0031-9317.2004.0272.x

[40] A. J. Stewart, W. Chapman, G. I. Jenkins, I. Graham, T. Martin and A. Crozier, "The Effect of Nitrogen and Phosphorus Deficiency on Flavonol Accumulation in Plant Tissues," Plant Cell and Environment, Vol. 24, 2001, pp. 1189-1197.

[41] M. C. Martinez-Ballesta, L. Lopez-Perez, M. Hernandez, C. Lopez-Berenguer, N. Fernandez-Garcia and M. Carvajal, "Agricultural Practices for Enhanced Human Health," Phytochemistry Reviews, Vol. 7, No. 2, 2008, pp. 251-260. doi:10.1007/s11101-007-9071-3

[42] N. Candan and L. Tarhan, "The Correlation between Antioxidant Enzyme Activities and Lipid Peroxidation Levels in Mentha pulegium Organs Grown in $\mathrm{Ca}^{2+}, \mathrm{Mg}^{2+}$, $\mathrm{Zn}^{2+}$ and $\mathrm{Mn}^{2+}$ Stress Conditions," Plant Science, Vol. 165, No. 4, 2003, pp. 769-776. doi:10.1016/S0168-9452(03)00269-3

[43] M. Burger and L. E. Jackson, "Microbial Immobilization of Ammonium and Nitrate in Relation to Ammonification and Nitrification Rates in Organic and Conventional Cropping Systems," Soil Biology and Biochemistry, Vol. 35, No. 1, 2003, pp. 29-36. doi:10.1016/S0038-0717(02)00233-X

[44] C. Tu, J. B. Ristaino and S. Hu, "Soil Microbial Biomass and Activity in Organic Tomato Farming Systems: Effects of Organic Inputs and Straw Mulching," Soil Biology and Biochemistry, Vol. 38, No. 2, 2006, pp. 247-255. doi:10.1016/j.soilbio.2005.05.002

[45] M. J. Harrison and R. A. Dixon, "Isoflavonoid Accumulation and Expression of Defense Gene Transcripts during the Establishment of Vesicular-Arbuscular Mycorrhizal Associations in Roots of Medicago truncatula," Molecular Plant-Microbe Interactions, Vol. 6, 1993, pp. 643-654. doi:10.1094/MPMI-6-643

[46] T. S. Walker, H. P. Bais, E. Grotewold and J. M. Vivanco, "Root Exudation and Rhizosphere Biology," Plant Physiolgy, Vol. 132, 2003, pp. 44-51. 